\title{
Treatment and Regression of Transmissible Venearal Tumour in Dogs
}

\author{
Nwoha R. I. O * \\ Department of Veterinary Medicine, Michael Okpara University of Agriculture Umudike. P.O. Box 824, Nigeria \\ Email: rosemarynwoha@yahoo.com
}

\section{Onyegbula 0.}

Department of Veterinary Public Health, Michael Okpara University of Agriculture Umudike. P.O. Box 824, Nigeria

\section{Daniel G. I.}

Department of Veterinary Pathology, Michael Okpara University of Agriculture Umudike. P.O. Box 824, Nigeria

\section{Article History}

Received: July 27,2021

Revised: September 10, 2021

Accepted: September 13, 2021

Published: September 16, 2021

\begin{abstract}
Antimicrobial resistance threatens the effective treatment of vast range of bacterial, fungi and viral diseases. Transmissible venereal tumour (TVT) is one of the highly contagious tumour in dogs commonly affecting sexually active stud and bitches. The disease was observed in a male and female Alsatian of about 3 years of age. Both dogs were sexually active and are utilized for breeding purposes. Samples were collected from the TVT growth on both the female and male genitalia. The samples were subjected to cytology and confirmatory diagnosis was made on the gross appearance of cauliformlike lesion and appearance of roundish cells with multiple vacuoles in the cytoplasm of the TVT tumour cells. Treatment was achieved by 3 doses of Vincristin sulphate injection USP $1 \mathrm{mg} / \mathrm{ml}$ Vinlon TM 1 intravenously through a cannula. There was no report of recrudesce of growth post treatment. Conclusion: TVT appear to exhibit genetic preference for sexually active Alsatian breed of dogs within the age bracket of 3 years and above. Despite the confronting challenge of drug resistance in medicine, intravenous administration of vincristine sulphate has remained efficacious in achieving complete regression of TVT the growth in dogs.
\end{abstract}

Keywords: Transmissible venereal tumour; Dogs; Alsatian.

\section{Introduction}

Antimicrobial resistance is a global public health menace resulting to ineffectiveness of drugs and persistence of infection [1]. Microorganisms that develop antimicrobial resistance are referred to as "Superbug" and presently new resistance mechanisms are emerging and spreading globally resulting in protracted illness, disability and death [1]. Transmissible venereal tumour commonly known as TVT is an oncogenic tumour disease that is venereally transmitted in domestic dogs and in other canids such as grey wolves and coyotes [2]. The disease is also referred to as Stickers Sarcoma transmitted only through grafting of tumour cells from infected dogs to naïve and susceptible dogs $[2,3]$. This finding was in contrast with the earlier belief that TVT was caused by a papilloma virus. Evidences to support the earlier statement have been made by several authors [4]. The disease is often observed as a visible cauliform-like growth on the external genitalia of both female and male dogs. In order cases, it may simply appear as genital bleeding due to the fragile nature of the tumour which easily soughs off on slight friction leaving an ulcerated surface. TVT is common in matured dogs and often takes advantage of the popular sire used in breed ing programs through which infection is transferred to several bitches [4]. TVT may regress naturally in an infected dog after several months of acquiring sufficient immunity against the disease [5]. In rare cases it may become metastatic and may spread to various parts of the body including the skin, brain, eyes, lymphnodes, liver, muscles, viscera, lungs, nose, face and internal organs [4, 6-9]. Such metastasis usually occurs in the immunocompromised dogs [10]. Diagnosis is made by cytology and identification of characteristic TVT cells with large vacuoles on a stained slide. The cells are identified as round cell tumours which is related to other malignant round cell such as mast cell tumour [4]. The condition can equally be identified morphologically by its cauliform- like appearance. Several drugs such as vincristine sulphate, doxorubicin, radiation, surgery, combination of vincristine and IL-2 have been used with varying success $[4,11]$. It is important to note the possibilities of recur especially in poorly treated cases. The aim of the study was to ascertain the possible effect of drug resistance on vincristine sulphate in the treatment of transmissible venereal tumour in dogs.

\section{Ethical Use of Animal}

The animals used in the case report was as recommended by the Animal Welfare Act, The Animals (Scientific Procedures) Act (Amendment) Order 1993, The EU parliament directive on the protection of animals used for scientific purposes and ARRP policies and guidelines. 


\section{Case Report}

Suspected cases of transmissible venereal tumour were presented at the veterinary clinic on the $3^{\text {rd }}$ of June 2019 and $15^{\text {th }}$ of August, 2020. The first case was identified on a 3-year-old adult male Alsatian sire used in dog breeding. The client complained of a growth on the penis weeks ago which he presented to a quack for treatment without success. The dog was up to date with vaccination, had good appetite for food and water. No apparent change in the sire's demeanour apart from intermittent bleeding in drops since the development of the growth.

The second case was presented in a female Alsatian bitch of about 3 years of age. The bitch had whelped only once the previous year. The bitch was fed leftover food from eateries and on anything edible. The client noticed constant blood stain from the vagina of the bitch and initially thought it was a sign of heat. The bitch defecates brownish and well-formed faeces. Had good appetite for food and water.

Physical examination in the first case revealed the following: good body condition, dripping of serosanguinous exudate from the prepuce, moderate sized pale coloured friable cauliform-like growth on the prepuce and reddish growth on the penis. The sire was alert and bright and weighed $45 \mathrm{~kg}$.

Clinical examination revealed: Temperature $38.7^{\mathrm{oC}}$, Heartrate $144 \mathrm{bpm}$, pulse rate $144 \mathrm{bpm}$, respiratory rate 56 cycles/min, mucous membrane=pinkish.

Physical examination of the bitch revealed the following: good body condition, constant dropping of dark red blood from the vagina, small bright reddish friable growth on the surface of the vagina. The bitch was alert and bright and weighed $22 \mathrm{~kg}$.

Clinical examination revealed the following: Temperature $39.4^{\mathrm{oC}}$, heart rate $120 \mathrm{bpm}$, pulse rate $130 \mathrm{bpm}$, mucous membrane=pinkish

Tentative diagnosis of TVT was made on both cases and growth samples were collected for histiocytologic examination in the laboratory.

Figure-1. Reddish coloured TVT tumour growth on the tip of the penis of an adult male Alsatian sire and pinkish cauliflowerlike growth on the prepuce

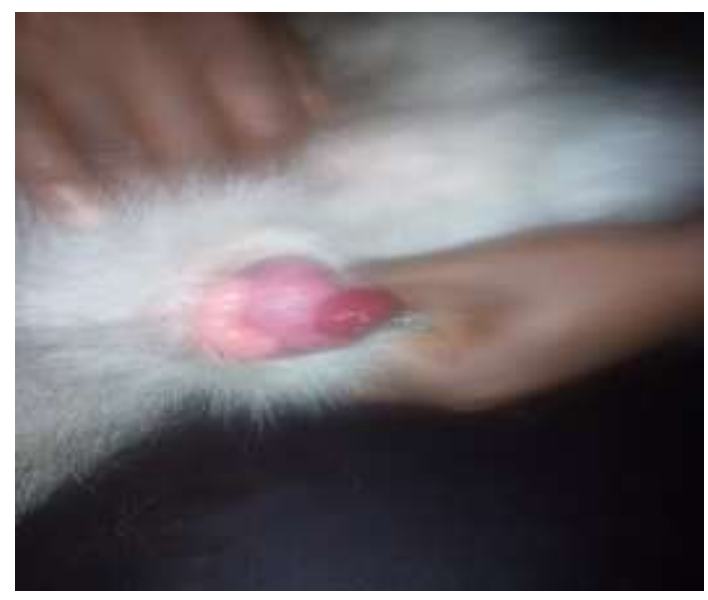

Figure-2. Reddish coloured TVT growth on the vagina of an adult Alsatian bitch

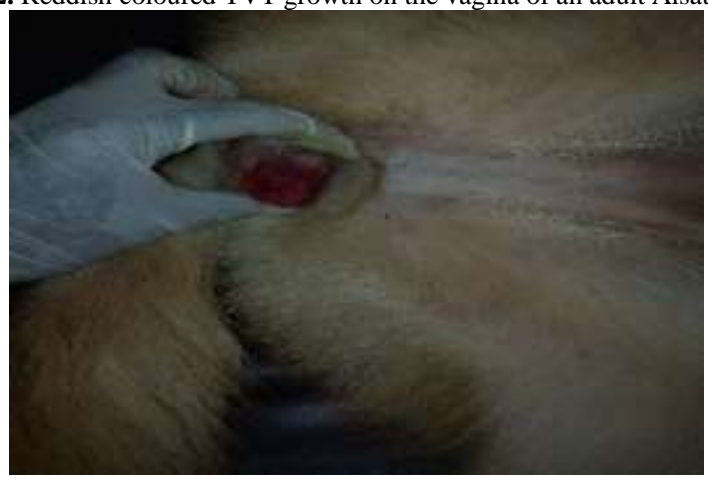

Figure-3. Vincristin sulphate induced cellulitis and oedema on the left limb of the adult male Alsatian sire

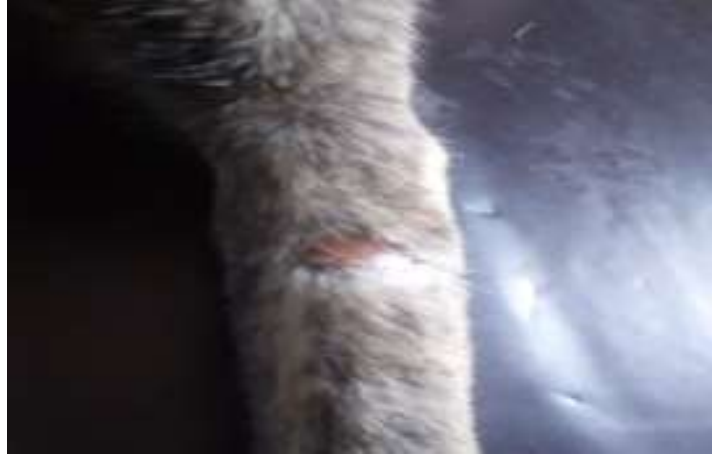


Sumerianz Journal of Agriculture and Veterinary

Table-1. Result of haematology on the first case (Male Alsatian sire)

\begin{tabular}{l|l}
\hline HB 11.3g/dl (12-18) & Metamyelocyte 15(2.27) \\
\hline PCV 30.00\% (37-55) & WBC 15.10 $\times 10^{3} / \mu \mathrm{L}$ \\
\hline MCV 67.11fL (60-70) & Bands Neutrophils 9\%(1.36) $\times 10^{3} / \mu \mathrm{L}(0-299)$ \\
\hline MCH 25.48pg & Segmented Neutrophils 59\% $(8.91) \times 10^{3} / \mu \mathrm{L}(3000-12000)$ \\
\hline MCHC 37.97 g/dl (30-60) & Lymphocytes 14\%(2.11) $\times 10^{3} / \mu \mathrm{L}(2,500-7,500)$ \\
\hline & Monocytes 1\%(0.15) $\times 10^{3} / \mu \mathrm{L}(0-200)$ \\
\hline & Eosinophils 0\%(0) $\times 10^{3} / \mu \mathrm{L}(0-2,400)$ \\
\hline & Basophils $1 \%(0.15) \times 10^{3} / \mu \mathrm{L}(0)$ \\
\hline
\end{tabular}

\section{Cytology}

Appearance of roundish cells with multiple vacuoles in the cytoplasm characteristic of TVT tumour cells. Few inflammatory cells, neutrophils and polymorphonuclear cells.

Table-2. Result of haematology on the second case (Female Alsatian bitch)

\begin{tabular}{|c|c|}
\hline $\mathrm{RBC} 4,01 \times 106 / \mu \mathrm{L}(5.5-8.5)$ & Myelocyte $2(0.15)$ \\
\hline HB $11.1 \mathrm{~g} / \mathrm{dl}(12-18)$ & Metamyelocyte 19(2.27) \\
\hline PCV $29.00 \%(37-55)$ & WBC $12.10 \times 10^{3} / \mu \mathrm{L}(5,500-16,900 / \mu \mathrm{L})$ \\
\hline MCV 65.11fL (60-70) & Bands Neutrophils $8 \%(1.36) \times 10^{3} / \mu \mathrm{L}(0-299)$ \\
\hline MCH 25.38pg & Segmented Neutrophils 55\% (8.91) $\times 10^{3} / \mu \mathrm{L}(3000-12000)$ \\
\hline \multirow[t]{4}{*}{ MCHC $33.87 \mathrm{~g} / \mathrm{dl}(30-60)$} & Lymphocytes $12 \%(2.11) \times 10^{3} / \mu \mathrm{L}(2,500-7,500)$ \\
\hline & Monocytes $2 \%(0.15) \times 10^{3} / \mu \mathrm{L}(0-200)$ \\
\hline & Eosinophils $0 \%(0) \times 10^{3} / \mu \mathrm{L}(0-2,400)$ \\
\hline & Basophils $0 \%(0.15) \times 10^{3} / \mu \mathrm{L}(0)$ \\
\hline
\end{tabular}

\section{Cytology}

Appearance of roundish cells with large vacuoles in the cytoplasm characteristic of TVT tumour cells. Few inflammatory cells and neutrophils.

From the result and gross appearance of the tumour growth, a confirmatory diagnosis of TVT tumour was made.

\section{Therapy}

In both cases, treatment was achieved using vincristine sulphate injection USP1mg/ml Vinlon ${ }^{\mathrm{TM}} 1$ intravenously given 3 doses in the male sire and 2 doses in the bitch at one-week interval in both dogs. The drug was administered intravenously in the bitch with a cannula throughout the course of the treatment. The use of cannula in the administration of vincristine in the stud Alsatian only commenced by the second week of treatment. The first treatment was administered through direct veni puncture into the blood vessel. By 5 days' post initial treatment by veni puncture, there was development of oedema on the affected left limb from the ankle to the paw and also evidence of cellulitis at the site of injection (Fig.3). The appetite was diminished, well-formed faeces and adequate micturition with yellowish discolouration of the urine. There was loss of weight $35 \mathrm{~kg}$, by the second week of treatment, temperature $39.0^{\circ \mathrm{C}}$, heart rate $120 \mathrm{bpm}$, pulse rate $120 \mathrm{bpm}$. The second dose of treatment was extended further to 2 weeks to allow for healing of the drug induced injury on the limb. Post administration of the second dose, there was no apparent regression of the tumour growth (Fig 1). However, by third dose post treatment there was significant regression of the TVT growth leaving only a small stump of growth. By the fourth and final dose, there was complete disappearance of the TVT growth. The blood picture show fall in PCV level, normal values of white blood cells and high levels of metamyelocytes (Table 1).

For the second case on the bitch (fig 2), only the first dose of vincristine injection was given to achieve near complete regression of the tumour growth. The blood picture revealed decrease in the pack cell volume (PCV) (Table 2) and high numbers of myelocytes $2(0.15)$ and metamyelocyte $19(2.27)$. The treatment was discontinued due to failure of client to present the patient for further treatment due to financial constraint and assumption that the first treatment would completely regress the TVT growth.

\section{Discussion}

In the cases presented above, TVT appear to have affinity for the genitalia of mostly sexually active dogs (Fig 1, Fig 2) [12]. As is case in most transmissible venereal disease of dogs, the tum our cell takes advantage of the popular sire effect, where by a preferred infected male stud is used to breed several female bitches thereby transferring the disease to susceptible bitches in dog populations. This is one of the most challenging disease amongst dog breeders in various geographical regions as their priced dogs are constantly at risk of either contracting or transferring TVT during breeding process. Because of the prevalence of TVT amongst dog breeder, most of them are very aware of the disease and are often the first to recognize the condition and diagnose to a clinician. They however are handicapped when it comes to prevention and control of TVT as most of them accept to breed just any bitch for financial gain. TVT is not very common in household pets except those owned by less aware owners who indiscriminately breed their pets with just any bitch or stud as the case may be. Transmissible venereal tumour is not contagious and viral induced and cannot be easily spread from an infected dog to another except through coitus and 
harvest of tumour cells to another dog [4]. This was confirmed by the evidence of a unique long interspersed nuclear element insertion close to the C-myc gene which is characteristic of TVT cells different from host cell round cell neoplasm [4]. Evidently, TVT cells possess 56 or less number of chromosomes whereas the normal dog cells apart from the sex cells possess 76 chromosomes indicating that TVT cells are grafted cells from a dog to another and did not arise from malignant transformation of squamous cells [4]. In both cases of TVT presented, Alsatian breed of dog appear to be highly susceptible to TVT than other breeds due to the rate of occurrence in the breed. Often TVT is self-limiting when infected dog would have developed adequate cellular immunity against the tumour which results to spontaneous regression [5]. The immunocompromised dogs and the breed susceptible such as the Alsatian would require chemotherapy [8].

Transmissible venereal tumour can be treated through surgery however the option often results to recrudescence of the tumour growth. Some studies have recorded cases of recurrence of TVT in surgically treated dogs [4]. The TVT cells are friable and easily breaks off during surgery thereby grafting life tumour cells to surrounding tissues. The contaminated tissues with time develop into fresh TVT growth. The best approach to surgery option is to follow up with chemotherapy [13]; Rob and Joyce, 2008). The rate of recurrence is often high in the immunocompromised and breed susceptible than in healthy dogs. There are several chemotherapeutic agents such as doxorubicin, vinblastine or bleomycin used in the treatment of TVT in dogs [4, 5]. Other drugs such as cyclophosphamide, azithromycin and methotrexate have also been used [6]. Vincristine sulphate is the preferred drug of choice commonly used in chemotherapy of TVT in dogs $[4,11,14]$ and its use in the cases presented achieved high success in the treatment. Efficacy of vincristine sulphate could be enhanced by its combination with IL2 and administered intratumoural in the TVT lesion [11]. Vincristine sulphate is corrosive and should be administered through cannula to prevent extravasation of the drug into the surrounding tissue which result to painful sloughing of cells and swelling as observed in the stud dog (Fig 3.). The tissue damage was handled with furosemide tablet at the dose of $2 \mathrm{mg}$ twice daily for two days. The left limb oedema and cellulitis was resolved within few days of treatment. The regression of TVT tumour growth usually commence by the second or third dose of the drug depending on the size of the growth. Often the drug is recommended at the dose of $1 \mathrm{mg} / \mathrm{ml}$ at once given intravenously at weekly interval for 3 to 6 months' post regression of the growth to prevent recurrence [4, 15]. In the two cases presented, although there was regression of the TVT growth by the second and third doses of vincristine sulphate, the treatment was not completed on the bitch due to financial constraint on the client and negligence. A disposition which may predispose the bitch to recurrence of the TVT tumour growth. The fall in the PCV levels of the stud (Table 1) and bitch (Table 2) were due to constant haemorrhage from the TVT lesion in the dogs. The increase in the level of metamyelocytes and the myelocytes signifies presence of ongoing infection in the dogs.

In conclusion, the present case report established breed related susceptiblity of Alsatian to TVT and sustained efficacy of vincristine sulphate in the treatment of TVT in dogs even in the current challenge of drug resistance in medicine.

\section{Acknowledgement}

The authors wish to acknowledge all that contributed towards the success of the paper.

\section{Conflict of Interest}

The authors of this paper declare no conflict of interest.

\section{References}

[1] WHO, 2020. Antimicrobial resistance. World Health Organization Facts Sheet.

[2] VonHoldt, B. M. and Ostrander, E. A., 2006. "The singular history of a canine transmissible tumour." Cell, vol. 126, pp. 445-447.

[3] Murgia, C., Pritchard, J. K., and Kimsy, 2006. "Clonal origin and evolution of a transmissible cancer." Cell, vol. 126, pp. 447-487.

[4] Maxey, L. and Wellmen, M., 2020. Judith Radin in Cowell and Tyler's diagnostic cytology and hematology of the dog and cat. 5 th edition ed.

[5] Stettner, N., Brenner, O., Eilam, R., and Harmelin, A., 2005. "Pegylated liposomal doxorubicin as a chemotherapeutic agent for treatment of canine transmissible venereal tumor in murine models." J. Vet. Med. Sci., vol. 67, pp. 1133-9.

[6] MacEwen, G., 2001. Transmissible venereal tumor. In:Small animal . Clinical oncology. 3rd edition ed. Philadelphia: Pa:WB Saunders CO., pp. 651-655.

[7] Henson, L. L., 2001. Reproductive system.In: Atlas of canine and feline cytology. Philadelphia: Pa:WB Saunders CO., pp. 296-297.

[8] Arif, S. A., 2017. "Clinco-pathological study on metastatic form of Canine Veneral Tumor (TVT) and its therapeutic management." International Journal of Chemical Studies, vol. 5, pp. 593-595.

[9] Marcos, R., Santos, M., and Marrinhas, C., 2006. "Cutaneous transmissible venereal tumor without genital involvement in a prepubertal female dog." Veterinary Clinical Pathology, vol. 35, pp. 106-109.

[10] Bosco, C. M. and Ververidis, H. N., 2004. "Clinical TVT-Clinical findings, diagnosis and treatment." In World Small Animal Veterinary Association World Congress Proceedings.

[11] Den Otter, W., Hack, M., Jacobs, J. J., Tan, J. F., Rozenaal, L., and Van Moorselaar, R. J., 2015. "Effective treatment of Transmissible venereal tumour in dogs with vincristine and IL2." Anticancer Research, vol. 35, pp. 3385-3391. 
[12] Dingli, D. and Nowak, M. A., 2006. "Cancer biology: infectious tumour cells." Nature, vol. 443, pp. 35-6.

[13] Ettinger, Stephen, J., Feldman, and Edward, C., 1995. Textbook of veterinary internal medicine. 4th ed. ed. W.B. Saunders Company.

[14] Mello, M. M. I., de Souza, F., Ferreira, and Gobello, C., 2005. Canine transmissible venereal tumor: Etiology, pathology, diagnosis and treatment. Recent Advances in Small Animal Reproduction.

[15] Rogers, K., Walker, M., and Dillon, H., 1998. "Transmissible venereal tumor: a retrospective study of 29 cases." Journal of the American Animal Hospital Association, vol. 34, pp. 463-70. 